\title{
Molecular cloning and expression analyses of RPS $3 a$ gene from mulberry under abiotic stresses and among different mulberry varieties
}

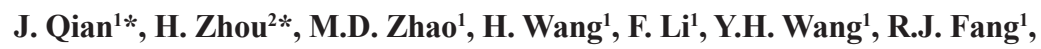 \\ W.G. Zhao ${ }^{1}$ and H.J. Kim ${ }^{2}$ \\ ${ }^{1}$ School of Biology and Technology, \\ Jiangsu University of Science and Technology, Zhenjiang Jiangsu, China \\ ${ }^{2}$ Department of Chemical Engineering, Kongju National University, Cheonan, \\ Chungnam Korea \\ *These authors contributed equally to this study. \\ Corresponding authors: W.G. Zhao / H.J. Kim \\ E-mail: wgzsri@126.com / hkim@kongju.ac.kr \\ Genet. Mol. Res. 15 (2): gmr. 15028129 \\ Received November 25, 2015 \\ Accepted January 18, 2016 \\ Published April 27, 2016 \\ DOI http://dx.doi.org/10.4238/gmr.15028129
}

\begin{abstract}
A full-length cDNA sequence coding ribosomal protein S3a of mulberry tree, which we designated MmRPS3a (GenBank accession No. KR610331), was cloned based on mulberry expressed sequence tags. Sequence analysis showed that the MmRPS3a is 1089 bp long and contains a 80-bp 5'-UTR (untranslated region) and a 220bp 3'-UTR. Its open reading frame consists of a 789-bp encoding 262 amino acids with a predicted molecular weight of $30.053 \mathrm{kDa}$ and an isoelectric point of 9.84. Homology analysis revealed that MmRPS3a gene is highly conservative in mulberry and other species including Morus notabilis, Theobroma cacao, and Ricinus communis. Phylogenetic analysis based on MmRPS3a of other species showed that mulberry had a closer relationship with Prunus persica, Arabidopsis
\end{abstract}


thaliana, Solanum tuberosum, Solanum lycopersicum, and Vitis vinifera. The results of quantitative PCR analysis showed that the transcriptional level of MmRPS3a mRNA changed significantly under the conditions of hypothermia, aridity, salt stress, and varieties of differing resistances.

Key words: Morus multicaulis; MmRPS3a; Gene clone; Stress-induced expression

\section{INTRODUCTION}

Ribosomal proteins are a conserved family in biological evolution and have been found in eighty kinds of eukaryotic cells. They are the key components of ribosomes and play a critical role in protein biosynthesis and function (Wool, 1996, Lindström, 2009). Particles composed of four kinds of rRNA and seventy types of proteins are the sites of protein synthesis. The biological activity of ribosomes is coordinated with the demand of protein synthesis in cells. Cell hyperplasia activity will be accompanied by elevated biological activity of ribosome. RPS3a is located on the contact surface of the $40 \mathrm{~S}$ and $60 \mathrm{~S}$ subunits. It is a highly conserved protein which composes the 40S subunit of a molecular weight of about $29.8 \mathrm{kDa}$. RPS3a can combine with transcription initiation factors such as eIF-2, eIF-3, eEF-2, tRNA, mRNA, 18S RNA etc Studies have shown that the activity of ribosomal protein S3a in cell metabolism, apoptosis and the body's immune system is closely related to signal transduction. It is a multifunctional protein that can regulate transcription, RNA processing, DNA replication and other functions. It affects the initiation of ribosomal translation, regulates the synthesis of specific important proteins, and participates in cell growth and differentiation (Cordeiro-da-Silva al., 2001; Shin et al., 2009).

Previous studies have shown that ribosomal protein S3a was closely related to cell cycle regulation, cell apoptosis, immunity and signal transduction etc. (Naora et al., 1998; Chen and Ioannou, 1999; Hu et al., 2000; Lopez et al., 2002; Xu et al., 2005). Sun and Ma (2002) prepared RPS3a and its antibody by a GST gene fusion protein system. They detected its expression in the whole process of apoptosis by western blot and explored the possible biochemical pathways and mechanisms of apoptosis. The results showed that ribosomal protein S3a was located on the contact surface of the $40 \mathrm{~S}$ and 60S subunits where ribosomes combined with translation initiation factors eIF2, eIF3, Met-tRNA, Phe-tRNA and mRNA. Therefore, RPS3a changes would affect the initiation of ribosomal translation and RPS3a could inhibit the synthesis of specific important proteins and alter normal cell metabolism, which may lead to apoptosis. The level of ribosomal protein S3a could therefore play important roles both in the biochemical component of apoptosis and in cell function. The level of ribosomal protein S3a level also plays an important functional role in the biochemical pathway of apoptosis.

The ribosomal protein S3a gene has been successfully cloned and analyzed from higher mammalian to lower bacterial species (Rebane et al., 1998; Zemzoumi et al., 1999; Ouarzane et al., 1998; Shemer et al., 2000; Lyamouri et al., 2002). Other ribosomal functions of RPS3a have also been verified (Warner and McIntosh, 2009). In wild tussah silk insects (Antheraea pernyi), the whole sequence of the RPS3a gene has been cloned and its expression analyzed. The study showed that the amino acid sequence of tussah RPS3a had a high degree of homology with the amino acid sequence of Actias selene Htibner (Zhu et al., 2010a,b). Phylogenetic tree analyses of tussah and other 10 species indicated that there was a clear branch among Lepidoptera, Diptera and vertebrates, but RPS3a amino acid sequences among 
different species were quite conservative in some regions. In addition, different species of the RPS3a terminal amino acids were also significantly different in number and variety. The study limitation was that the sample size was too small. Further studies are needed to explain if this difference can be used as evidence for genetic evolution. RT-PCR results showed that tussah RPS3a was constitutively expressed in fifth instar larvae tissue and it could be associated with extraribosomal function (Ouarzane et al., 1998; Lyamouri et al., 2002).

In recent years, further studies have shown that ribosomal proteins not only played an important role in protein synthesis but also had unique extraribosomal functions (Cui et al., 2000). Studies on the extraribosomal functions of RPS3a focused on aspects of its tumor cell proliferation, differentiation, apoptosis etc. (Russell et al., 2000). It is not clear whether the plant RPS3a gene is involved in stress response. In this study, a full-length cDNA sequence coding ribosomal protein S3a of mulberry tree, which we designated MmRPS3a, was cloned based on mulberry expressed sequence tags (ESTs). Bioinformatic analysis was used to analyze its sequence and to detect the variation of transcriptional level of RPS3a mRNA under the conditions of hypothermia, aridity, salt stress and resistant and susceptible varieties using real time fluorescence quantitative PCR. Through the study of this gene one can understand the expression of the mulberry ribosomal protein S3a gene at the molecular level under different stress conditions, and its role and functions in mulberry. It would be helpful to explain further the resistance mechanism of mulberry and lay the foundation for developing resistant mulberry in the future via transgenic technology.

\section{MATERIAL AND METHODS}

\section{Plant materials and reagents}

To analyze gene expression under different conditions, mulberry (Morus multicaulus) variety Yu711 was grown under standard conditions at the National Mulberry Gene Bank of the Sericultural Research Institute, Chinese Academy of Agricultural Sciences, Zhenjiang, Jiangsu Province, China. The mulberry shoots were grafted, then transferred into an incubator maintained at $25^{\circ} \mathrm{C}$ under at welve-hour photoperiod to induce burgeoning growth. After fifty days in these conditions, the winter buds grew to about $30 \mathrm{~cm}$ in length.

RNAiso Plus, Reverse Transcriptase M-MLV (RNaseH-), RNase Inhibitor, dNTP, rTaq polymerase, T4 DNA ligase, Agarose Gel DNA Purification Kit and pMD18-T vectors were products of Takara Company. All PCR primers were synthesized by Shanghai Sangong Biological Engineering Technology and Services Co. Ltd., and all chemicals used were analytical grade reagents. Forward and reverse primers were designed according to the EST library of mulberry leaves.

\section{RNA isolation and cloning of the full-length cDNA}

For the drought treatment, mulberry cuttage seedlings were grown to a height of about $20 \mathrm{~cm}$. When the seedlings showed drought symptoms, about $100 \mathrm{mg}$ mulberry leaves were taken from the top shoots. RNAiso Plus reagent was used according to the manufacturer's protocol. The samples were resuspended in DEPC-treated water and stored at $-80^{\circ} \mathrm{C}$. The ratio of A260/A280 was used to express the RNA purity. Since the ratio of A260/A280 was found to be 1.8-1.9, all RNAs could be used in the experiments. 
The cDNA was synthesized from $9 \mu \mathrm{L}$ total RNA by Reverse Transcriptase M-MLV $\left(\mathrm{RNaseH}^{-}\right)$at $42^{\circ} \mathrm{C}$ for 60 min with $4 \mu \mathrm{L}$ oligo-dT-adaptor primer in $20 \mu \mathrm{L}$ system following the manufacturer's protocol. The cDNA was used as a template for PCR in gene cloning.

Forward and reverse primers were designed according to the EST with the inference function from the mulberry cDNA library.

Forward primer: MmRPS3a-F: 5'-TCTCCAACCCAAACCCTAACCCTAG-3'; Reverse primer: MmRPS3a-R: 5'-CAACATCCTCTGAGTAGTCACCGTG-3'.

The RT-PCR reactions were performed in a total volume of $50 \mu \mathrm{L}$ including $1 \mu \mathrm{L}$ first-strand cDNA, $41 \mu \mathrm{L} \mathrm{ddH_{2 }} \mathrm{O}, 1 \mu \mathrm{L}$ each of the gene-specific primers, $0.5 \mu \mathrm{L} d \mathrm{dTP}, 5 \mu \mathrm{L}$ buffer, and $0.5 \mu \mathrm{L}$ rTaq DNA polymerase $(5 \mathrm{U} / \mathrm{mL})$. The Gradient PCR amplifications were performed using the following parameters: DNA was denatured at $94^{\circ} \mathrm{C}$ for $5 \mathrm{~min}$ followed by two amplification cycles $\left(94^{\circ} \mathrm{C}\right.$ for $30 \mathrm{~s}, 56^{\circ} \mathrm{C}$ for $40 \mathrm{~s}, 72^{\circ} \mathrm{C}$ for $\left.1 \mathrm{~min}\right)$; then by thirty-five amplification cycles $\left(94^{\circ} \mathrm{C}\right.$ for $30 \mathrm{~s}, 56^{\circ} \mathrm{C}$ for $40 \mathrm{~s}, 72^{\circ} \mathrm{C}$ for $\left.1 \mathrm{~min}\right)$, with a final extension step for $10 \mathrm{~min}$ at $72^{\circ} \mathrm{C}$, with a final hold at $4^{\circ} \mathrm{C}$. The RT-PCR products were analyzed in $1 \%$ agarose gels and purified using Takara Agarose Gel DNA Purification Kit following the manufacturer's protocol. The purified fragment, which was confirmed to have the predicted length, was then cloned with the pMD18-T vector and sequenced to confirm the presence of an open reading frame (ORF) related to the tentative consensus sequence.

\section{3' cDNA end amplification of MmRPS3a}

The homologous comparison showed that the cDNA sequence of the MmRPS3a gene fragment obtained contained the complete 5'-UTR and incomplete 3'-UTR only. Nested reverse primers were designed according to the two sequences obtained, and 3'-RACE amplifications were performed. Total RNA, found using a browser, served as a template to generate first strand total cDNA using Clontech SMART ${ }^{\mathrm{TM}}$ RACE Kit (Clontech Laboratories Inc., USA). The EST of MmRPS3a sense primer was: GSP1: 5'- CTCCAACCCAAACCCTAACCCTAGC-3'.

The cDNA was synthesized from $9 \mu \mathrm{L}$ total RNA by Reverse Transcriptase M-MLV ( $\mathrm{RNase} \mathrm{H}^{-}$) at $42^{\circ} \mathrm{C}$ for 60 min with $4 \mu \mathrm{L}$ 3'ap primer in $20 \mu \mathrm{L}$ following the manufacturer's protocol. The cDNA was used as a template for 3'-RACEin gene cloning.

Forward and reverse primers were the Clontech SMART ${ }^{\mathrm{TM}}$ RACE KitGSP1and 3'-Primer. The 3'RACE-PCR reactions were performed in a total volume of $50 \mu \mathrm{L}$ including 1 $\mu \mathrm{L}$ first-strand cDNA, $41 \mu \mathrm{L} \mathrm{ddH_{2 }} \mathrm{O}, 1 \mu \mathrm{L}$ each of the gene-specific primers, $0.5 \mu \mathrm{L} d N T P, 5$ $\mu \mathrm{L}$ buffer, and $0.5 \mu \mathrm{L}$ rTaq DNA polymerase $(5 \mathrm{U} / \mathrm{mL})$. The Gradient PCR amplifications were performed using the following parameters: DNA was denatured at $94^{\circ} \mathrm{C}$ for $5 \mathrm{~min}$ followed by two amplification cycles $\left(94^{\circ} \mathrm{C}\right.$ for $40 \mathrm{~s}, 52^{\circ} \mathrm{C}$ for $40 \mathrm{~s}, 72^{\circ} \mathrm{C}$ for $\left.1 \mathrm{~min}\right)$; then by eighteen amplification cycles $\left(94^{\circ} \mathrm{C}\right.$ for $40 \mathrm{~s}, 50^{\circ} \mathrm{C}$ for $40 \mathrm{~s}, 72^{\circ} \mathrm{C}$ for $\left.1 \mathrm{~min}\right)$, with a final extension step of $7 \mathrm{~min}$ at $72^{\circ} \mathrm{C}$, with a final hold at $4^{\circ} \mathrm{C}$. The RACE products were analyzed using the methodologyas for the PCR products.

\section{Bioinformatics analysis of the MmRPS3a gene}

The sequence encoding MmRPS3a was determined by homology searches in the NCBI (http://www.ncbi.nlm.gov/) databases using the BLAST program and the homology sequences were downloaded from the database. Alignment of the MmRPS3a protein with other structurally related RD proteins was performed using the Clustal X program. Some other 
basic properties were analyzed by tools at the ExPASy website (http://www.expasy.org) and those of DNAStar software such as ORF searching and translation of nucleotide sequences, as well as prediction of isoelectric point and molecular weight of MmRPS3a. To determine the relationship between MmRPS3a and other MmRPS3a proteins, phylogenetic analysis was carried out by the MEGA 4.1 program (Tamura et al., 2007).

All sequences of other species obtained from Genbank were subjected to multiple sequence alignment using the Clustal W program (Thompson et al., 1994), then a phylogenetic tree of the amino acid sequences was constructed according to the neighbor-joining method. The reliability of the tree was assessed by a bootstrap analysis using one thousand replicates. The prediction of protein domains was carried out using the SMART (http://smart.emblheidelberg.de/) package and literature references. SWISS-MODEL (http://swissmodel.expasy. org/) was used to analyze the molecular modeling of MmRPS3a protein (Zhao et al., 2010).

\section{MmRPS3a expression patterns using qRT-PCR}

To reveal the putative biological function of the MmRPS3a protein, qRT-PCR was performed to detect the expression level of MmRPS3a mRNA under drought, low-temperature and salt stress conditions in mulberry. The qRT-PCR was performed on an optical 96-well plate with an Applied Biosystems 7300 Real-Time PCR System. The single-strand cDNA was synthesized following the directions of the Primescript RT Reagent Kit. PCR was carried out using the SYBR Premix Ex Taq Kit. The amplifications of qRT-PCR were performed using the following parameters: initial denaturation at $95^{\circ} \mathrm{C}$ for $10 \mathrm{~min}$, denaturation for 45 cycles at $95^{\circ} \mathrm{C}$ for $15 \mathrm{~s}$, primer annealing at $60^{\circ} \mathrm{C}$ for $1 \mathrm{~min}$, followed by primer extension at $95^{\circ} \mathrm{C}$ for 15 $\mathrm{s}, 60^{\circ} \mathrm{C}$ for $1 \mathrm{~min}, 95^{\circ} \mathrm{C}$ for $15 \mathrm{~s}$ and $60^{\circ} \mathrm{C}$ for $15 \mathrm{~s}$. All reactions were run in three times. The mulberry Maactin gene ( $\beta$-actin) (GenBank access No. DQ785808), a housekeeping gene, was used as an internal control to allow normalization by visual inspection of mRNA levels. Forward primer (Maactin-F: 5'-GACAATGGAACTGGAATGG-3') and Reverse primer (Maactin-R: 5'-GACCCTCCAATCCAGACA-3') were designed based on the Maactin gene.

When the buds grew to about $20 \mathrm{~cm}$ in length, the grafted seedlings were subjected to a series of stress treatments including drought (treatment times: 0, 2, 4, 6, 8, and 10 days), low temperature (treatment temperatures: $25,15,8,3,0$ and $1^{\circ} \mathrm{C}$ ) and salt stress with $300 \mathrm{mM}$ $\mathrm{NaCl}$ (treatment times: 0,12, 24, 48, 96, 144, 192, 264, 384 and $432 \mathrm{~h}$ ).

The plants were irrigated with appropriate amounts of $\mathrm{NaCl}$ solutions when the winter buds grew to about $20 \mathrm{~cm}$ in length. Stress was administered from the beginning of the photoperiod without changing light intensity, humidity or photoperiod. Control plants were maintained in the incubator at $25^{\circ} \mathrm{C}$ for a $12 \mathrm{~h}$ photoperiod without changing light intensity or humidity before RNA extraction. To identify the gene expression of mulberry varieties with differing resistances to bacterial blight (black withered type), five blight-resistant mulberries (Liaoyu 8, Liaoyu 166, Yishuihuanglutou, Daheisang, Wuer) and five blight-susceptible mulberries (Lvshenzi, Xiaohongdian, Tubai 1, Duoguosang, Zhongyang 1) were selected from the Zhenjiang National Mulberry GenBank in September 2013. For each of the two varieties, three plants were selected, then three to five branches were selected randomly from each of the selected plants. From the upper part of each branch, 1-3 leaves were harvested as experimental material. Total RNA was isolated from the tender buds of mulberry. Forward and reverse primers were designed for qRT-PCR according to the full-sequence of the MmRPS3a gene of mulberry (5'-3'): Forward primer (20 $\mu \mathrm{M})$ : qRPS3a-F: 5'-CACTGCCTCCACCTCTCCAA-3'; 
Reverse primer (20 $\mu \mathrm{M})$ : qRPS3a-R: 5'-CTTCCCTCCCTTCTTACCCTTC-3'.

The PCR result was analyzed using the Applied Biosystems 7300 System SDS Software with the assay of ddCt (Relative Quantitation). In the ddCt $(\Delta \Delta \mathrm{Ct})$ study, $\Delta \Delta \mathrm{Ct}=$ $\Delta \mathrm{Ct}$ sample $-\Delta \mathrm{Ct}$ control, $\Delta \mathrm{Ct}=\mathrm{Ct}$ sample $-\mathrm{Ct}$ actin and the $\mathrm{RQ}=2^{(-\Delta \Delta \mathrm{Ct})}$. In the control group, the $\Delta \Delta \mathrm{Ct}=0$ and $\mathrm{RQ}=1$. In the treatment group, we can get a relative value. In such a case, we can compare the levels of gene expression in the control and the treatment groups.

\section{RESULTS}

\section{Amplification of full-length cDNAs and sequence analysis of the MmRPS3a gene}

To clone the full-length cDNA of the mulberry MmRPS3a gene, a combination of bioinformatics analysis and the mulberry cDNA library screening technique were used. RT-PCR products were detected by $1 \%$ agarose gel, and yielded the expected size (Figure 1). Sequencing showed that the sequence was basically the same as the relevant EST. Nested amplification yielded a specific bright band of about $750 \mathrm{bp}$ which corroborated the homology-based length prediction (Figure 2). Sequence analysis showed that the isolated cDNA designated MmRPS3a is 1089 bp long and contains an 80-bp 5' untranslated region (5'-UTR) and a 220-bp 3'-UTR (Figure 3). Its open reading frame (ORF) is $789 \mathrm{bp}$ long, encoding 262 amino acids with a predicted molecular weight of $30.053 \mathrm{kDa}$ and an isoelectric point of 9.84. Online software Batch CDsearch (http://www.ncbi.nlm.nih.gov/Structure/cdd/wrpsb.cgi) analysis showed that the gene structure contains a conserved domain. The conserved domain database (CDD) is a protein annotation resource that consists of a collection of well-annotated multiple sequence alignment models for ancient domains and full-length proteins. These are available as position-specific score matrices (PSSMs) for fast identification of conserved domains in protein sequences via RPS-BLAST. CDD content includes NCBI (National Center for Biotechnology Information)curated domains, which use 3D-structure information to define domain boundaries explicitly and to provide insights into sequence-, structure- and function relationships as well as domain models imported from a number of external source databases.

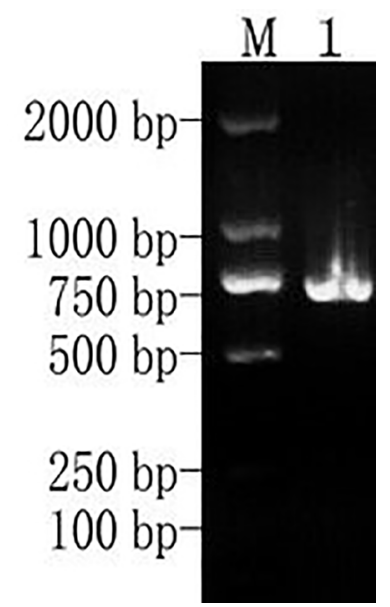

Figure 1. Electrophoretogram of amplification result of ORF of ribosomal protein S3a gene in Mulberry: lane $M=$ DL2000 DNA marker; lane 1 = Product of RT-PCR. 


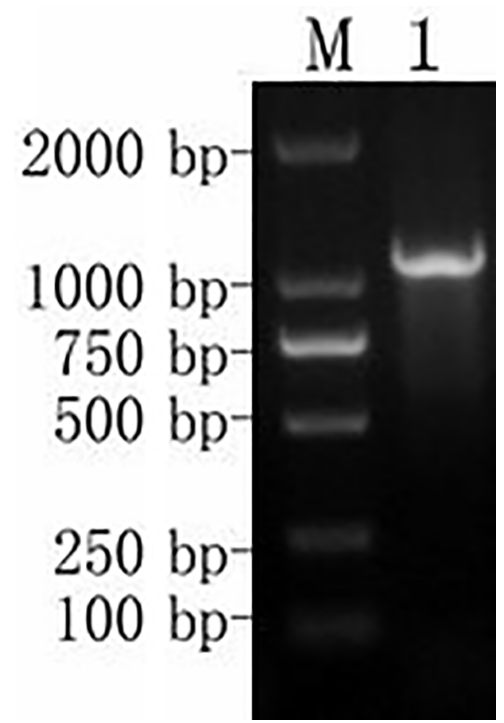

Figure 2. Amplification result of 3'-RACE: lane $M=$ DL2000 DNA marker; lane 1 = PCR amplification product.

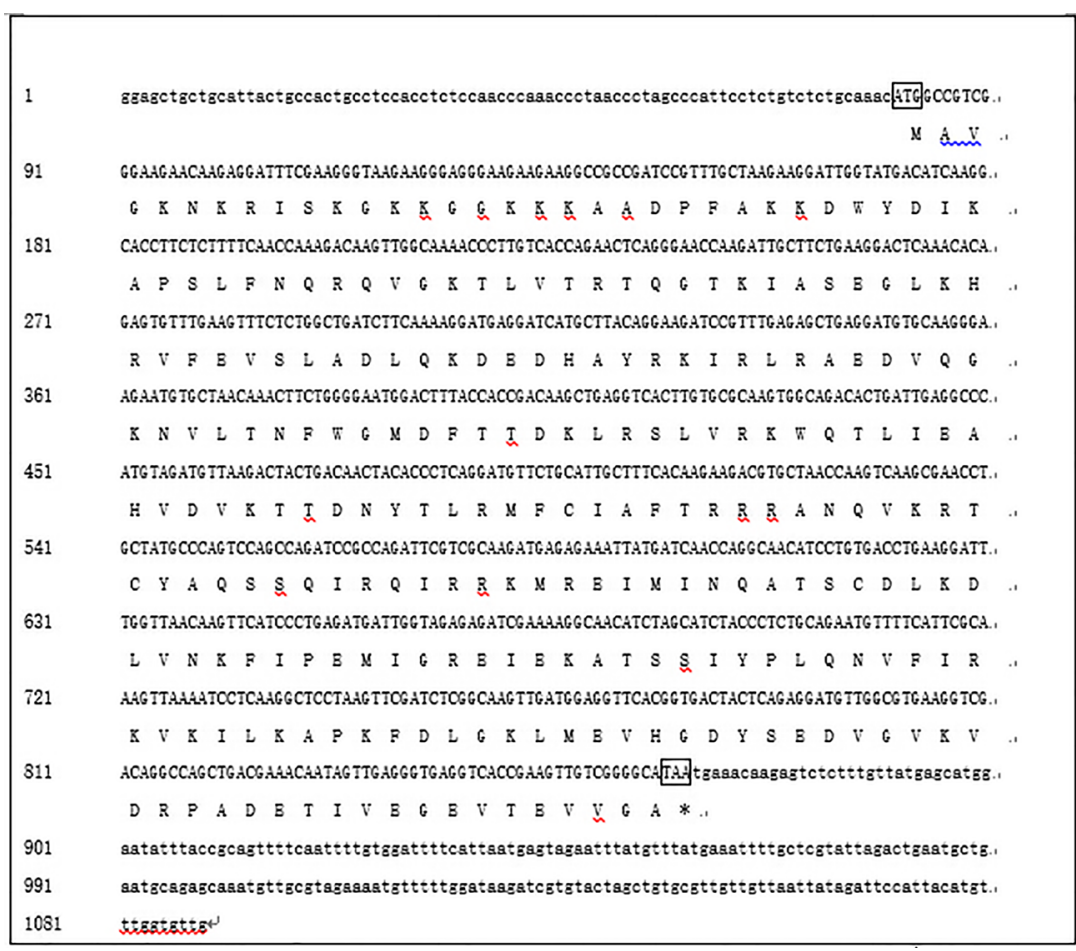

Figure 3. Full length cDNA sequence and deduced amino acids of the mulberry gene RPS3a. ATG indicates the start codon; TAA indicates the stop codon. 


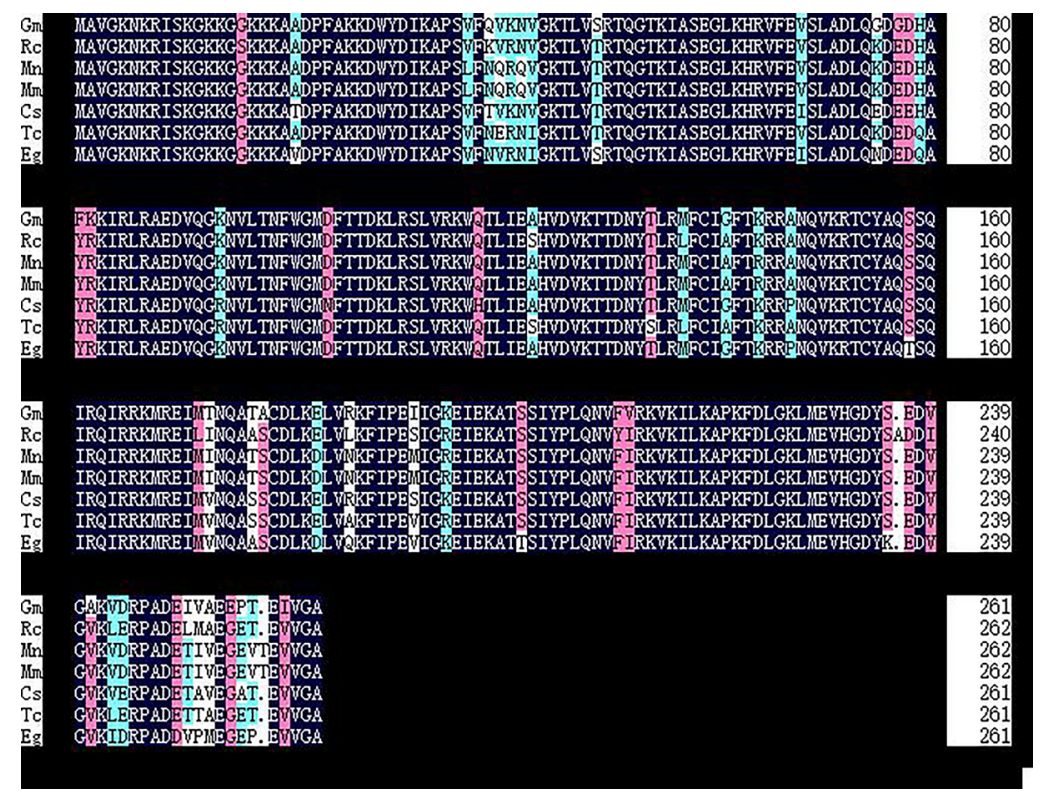

Figure 4. Multiple sequence alignment of amino acids encoded by the mulberry gene RPS3a.

\section{MmRPS3a gene}

In order to understand the structure of the amino acid sequence encoded by the mulberry P5CS gene, a homologous alignment was carried out using the Clustal x 2.0 program with the amino acid sequences of MmRPS3a and nine other species (Figure 4). The results show that the seven homologous sequences are relatively similar in length and structure. The amino acid sequence homology of mulberry MmRPS3a with Cucumis sativus, Elaeis guineensis and Glycine max was up to $90 \%$. With Ricinus communis, the homology was as high as $91 \%$, with Theobroma cacao gene it was $92 \%$, and with Morus notabilis it was $100 \%$. Homology analysis revealed that MmRPS3a is highly conserved among different species, but there are also certain differences.

Based upon the amino acid sequence derived from the gene MmRPS3a, fifteen species with homologous amino acid sequences were selected from the NCBI website and homology analysis was done to establish the evolutionary tree using MEGA5.1 Software (Figure 5). The results show in terms of the length and structure of the amino acid sequences for sixteen species are very conservative. There is relatively close homology between mulberry and Prunus persica, Arabidopsis thaliana, Solanum tuberosum, Vitis vinifera, Ricinus communis, and Theobroma cacao.

\section{Stress-induced expression patterns of MmRPS3a}

In order to investigate further whether the expression of $M m R P S 3 a$ was induced by abiotic stressors, we first monitored the mRNA transcript level of the MmRPS3a gene by qRT-PCR under different abiotic stress treatments including $\mathrm{NaCl}$, mulberry bacterial blight resistance, low temperature and aridity, until the appearance of symptoms (Figures 6, 7, 8 
and 9). As shown in Figure 6, the expression level of the MmRPS3a transcripts under $\mathrm{NaCl}$ treatment declined firstly and then rose to a high stable value. As shown in Figure 7, the expression level of theMmRPS3a transcripts in bacterial blight resistant mulberries was much lower than those of blight-susceptible mulberries.

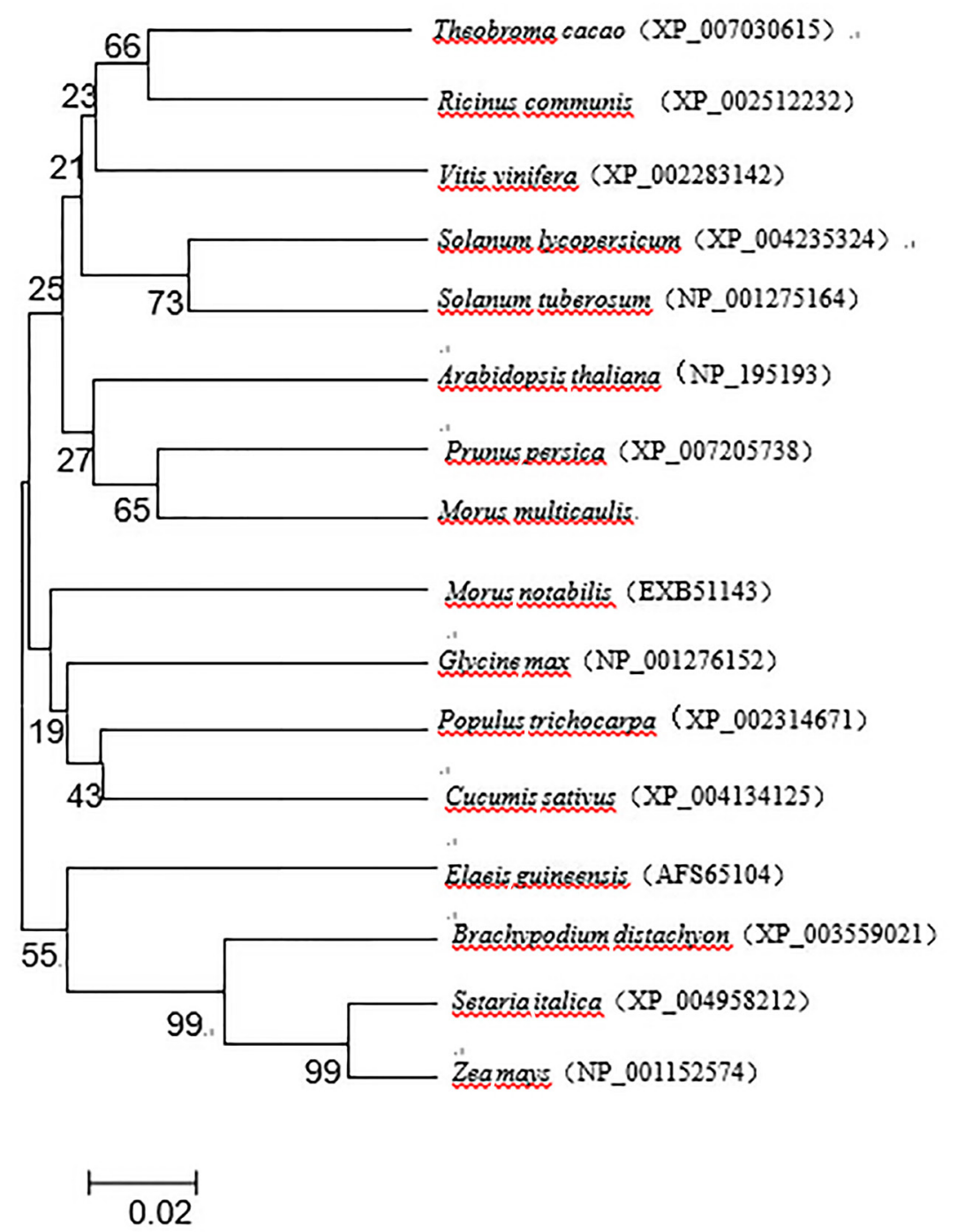

Figure 5. Phylogenetic tree based on amino acid sequence of RPS3a and other homologues sequences.

As shown in Figure 8, the expression level of the MmRPS3a transcripts under low temperature stress was unstable. It rapidly increased then decreased slowly, and fluctuated. As shown in Figure 9, the overall expression level of MmRPS3a transcripts surged at first, and then declined rapidly. 


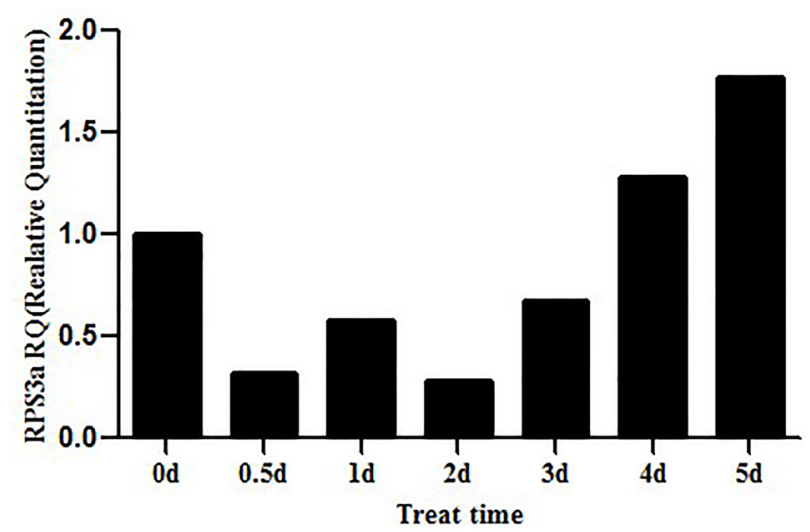

Figure 6. Quantitative RT-PCR analysis of RPS3a expression after salt treatment (treatment times 1:0 h, 2: 0.5, 3:1, $4: 2,5: 3,6: 4,7: 5$ days).

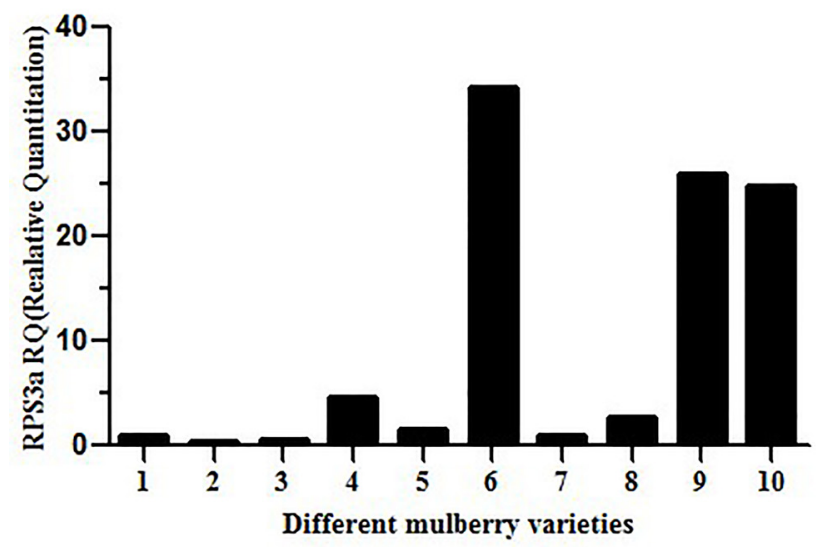

Figure 7. Quantitative RT-PCR analysis of RPS3a expression in mulberry varieties differing in blight resistance (treatment variety: column 1: Liaoyu 8, 2: Liaoyu 166, 3: Yishuihuanglutou, 4: Daheisang, 5: Wu er, 6: Lvshenzi, 7: Xiaohongdian, 8: Tubai 1, 9: Duoguosang, 10: Zhongyang 1).

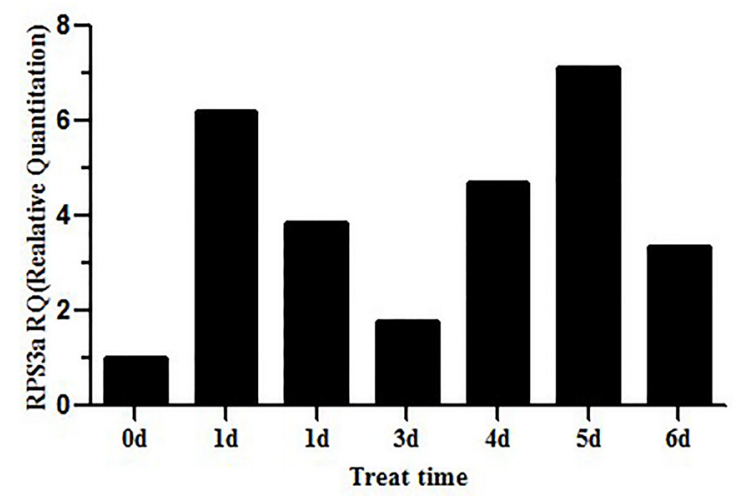

Figure 8. Quantitative RT-PCR analysis of RPS3a expression after low-temperature $\left(4^{\circ} \mathrm{C}\right)$ treatment; (treatment times $1: 0 \mathrm{~h}, 2: 1$ day, $3: 2,4: 3,5: 4,6: 5,7: 6$ days). 


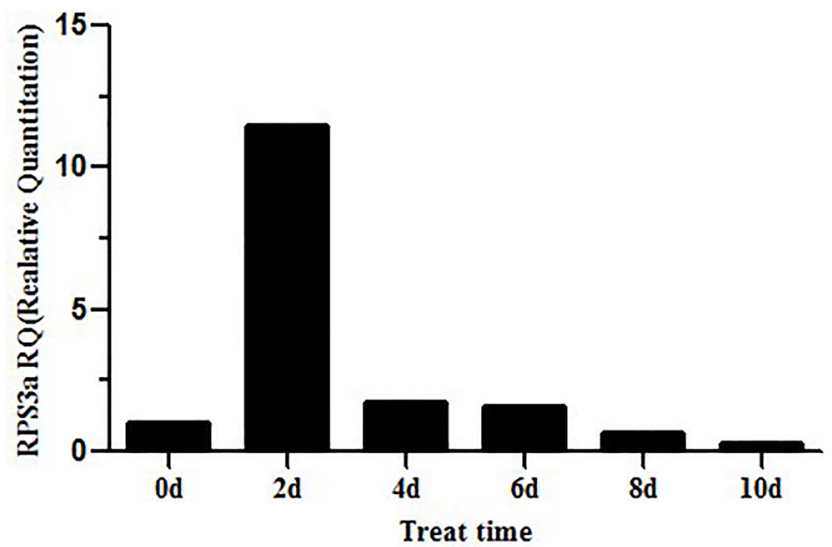

Figure 9. Quantitative RT-PCR analysis of RPS3a expression after drought treatment (treatment times 1:0 h, 2:2, $3: 4,4: 6,5: 8,6: 10$ days).

\section{DISCUSSION}

A ribosome is an intracellular particle mainly composed of ribosomal RNA and protein. Its most basic function is to collect and arrange amino acids for protein polypeptide chain synthesis in accordance with the instructions of messenger RNA. Therefore, a ribosome is a molecular machine for protein synthesis in the cell. Ribosomal proteins S3a (RPS3a) are widespread in both lower and higher organisms. RPS3a is one important member of the ribosomal proteins family. There are, however, relatively few studies on it currently, especially in plants. In this study, anMmRPS3a gene was isolated from the mulberry (Morus multicaulis) variety Yu711 then cloned. MmRPS3a belongs to the ribosomal protein family. Sequence analysis showed that MmRPS3a is 1089 bp long and contains an 80-bp 5'-UTR and a 220-bp 3'-UTR. Its ORF is of 789 bp encoding 262 amino acids with a predicted molecular weight of $30.053 \mathrm{kDa}$ and an isoelectric point of 9.84. Phylogenetic analysis based on the MmRPS3a genes in other species showed that mulberry shows a close relationship with Prunus persica and Arabidopsis thaliana, as well as Solanum tuberosum, Solanum lycopersicum, Vitis vinifera, Ricinus communis, Theobroma cacao and others.

The results of qRT-PCR analysis shows that the transcriptional level of MmRPS3a mRNA significantly changed under the conditions of $\mathrm{NaCl}$, mulberry bacterial blight resistance, low temperature and aridity stressors relative to the normal growth environment.

The amount of MmRPS3a expressed in $\mathrm{NaCl}$ stress declined initially, then rose to a relative maximum value and finally maintained a stable high value. This response was consistent with the report that plant RPS3a genes played an important role in changing the physiological mechanisms of adaptation to salinity (Wei et al., 2013).

The expression of MmRPS3a in mulberry varieties susceptible to bacterial blight was significantly higher than it was in blight-resistant varieties. The study speculated that the MmRPS3a gene was involved in certain physiological stress responses in mulberry disease. It was consistent with the study of Qi (2013) which described the expression mechanisms of peanut RPS3a gene under bacterial wilt stress.

Under low temperature stress, the amount of MmRPS3a expressed significantly 
fluctuated. The overall expression level of MmRPS3a transcripts surged initially then declined rapidly under drought stress. It is suggested that the extraribosomal function of RPS3a probably works to trigger the cells to apoptosis as a signal. As an important component of a ribosome, the irreversible degradation of RPS $3 a$ results in the disruption of the ribosome integrity, which inhibits protein synthesis and causes cell death.

In summary, further studies are still needed to verify if $R P S 3 a$ is a resistance gene under various stressors. Multi-factor experiments should be adopted to analyze the adaptation of plants under abiotic stress so research on MmRPS3a will become more rich and interesting.

\section{ACKNOWLEDGMENTS}

We thank anonymous reviewers and the editor for critically reviewing the manuscript. Research support by the Sericulture Industry Technology in China Program (\#CARS-22ZJ0308), the Public Industry (Agriculture) Specific Research Program (\#201403049), the Jiangsu Province Agriculture Science and Technology Support Program (\#BE2013330), the Crop Germplasm Resources Protection Project (Project \#2014NWB024), the Research and Innovation Project for College Graduates of Jiangsu Province (\#1252161418), the China Postdoctoral Science Foundation funded project (\#2014M551605), and the Natural Science Foundation of China (\#31400448).

\section{REFERENCES}

Chen FW and Ioannou YA (1999). Ribosomal proteins in cell proliferation and apoptosis. Int. Rev. Immunol. 18: 429-448. http://dx.doi.org/10.3109/08830189909088492

Cordeiro-da-Silva A, Borges MC, Guilvard E and Ouaissi A (2001). Dual role of the Leishmania major ribosomal protein S3a homologue in regulation of T- and B-cell activation. Infect. Immun. 69: 6588-6596. http://dx.doi.org/10.1128/ $\underline{\text { IAI.69.11.6588-6596.2001 }}$

Cui K, Coutts M, Stahl J and Sytkowski AJ (2000). Novel interaction between the transcription factor CHOP (GADD153) and the ribosomal protein FTE/S3a modulates erythropoiesis. J. Biol. Chem. 275: 7591-7596. http://dx.doi. org/10.1074/jbc.275.11.7591

Hu ZB, Minden MD, McCulloch EA and Stahl J (2000). Regulation of drug sensitivity by ribosomal protein S3a. Blood 95: 1047-1055.

Lindström MS (2009). Emerging functions of ribosomal proteins in gene-specific transcription and translation. Biochem. Biophys. Res. Commun. 379: 167-170. http://dx.doi.org/10.1016/j.bbrc.2008.12.083

Lopez CD, Martinovsky G and Naumovski L (2002). Inhibition of cell death by ribosomal protein L35a. Cancer Lett. 180: 195-202. http://dx.doi.org/10.1016/S0304-3835(02)00024-1

Lyamouri M, Enerly E and Lambertsson A (2002). Organization, sequence, and phylogenetic analysis of the ribosomal protein S3 gene from Drosophila virilis. Gene 294: 147-156. http://dx.doi.org/10.1016/S0378-1119(02)00763-1

Naora H, Takai I, Adachi M and Naora H (1998). Altered cellular responses by varying expression of a ribosomal protein gene: sequential coordination of enhancement and suppression of ribosomal protein S3a gene expression induces apoptosis. J. Cell Biol. 141: 741-753. http://dx.doi.org/10.1083/jcb.141.3.741

Ouarzane M, Labbé M and Péry P (1998). Eimeria tenella: cloning and characterization of cDNA encoding a S3a ribosomal protein. Gene 225: 125-130. http://dx.doi.org/10.1016/S0378-1119(98)00523-X

Qi W, Xiu ZW, Yue YT, Chuan TW, et al. (2013). Arachishypogaea 40S ribosomal protein RPS30 gene cloning and analysis. In: China Crop Science Society 2013 Academic Annual Meeting Abstract Book.

Rebane A, Tamme R, Laan M, Pata I, et al. (1998). A novel snoRNA (U73) is encoded within the introns of the human and mouse ribosomal protein S3a genes. Gene 210: 255-263. http://dx.doi.org/10.1016/S0378-1119(98)00070-5

Russell L, Naora H and Naora H (2000). Down-regulated RPS3a/nbl expression during retinoid-induced differentiation of HL-60 cells: a close association with diminished susceptibility to actinomycin D-stimulated apoptosis. Cell Struct. Funct. 25: 103-113. http://dx.doi.org/10.1247/csf.25.103 
Shemer R, Eibschitz I and Cavari B (2000). Isolation and characterization of medaka ribosomal protein S3a (fte-1) cDNA and gene. Gene 250: 209-217. http://dx.doi.org/10.1016/S0378-1119(00)00185-2

Shin HS, Jang CY, Kim HD, Kim TS, et al. (2009). Arginine methylation of ribosomal protein S3 affects ribosome assembly. Biochem. Biophys. Res. Commun. 385: 273-278. http://dx.doi.org/10.1016/j.bbrc.2009.05.055

Sun AP and Ma HX (2002). The RPS3a level in the process of cellular apoptosis: III. Detection of RPS3a level changes in apoptosis. Heilongjiang Med Pharm. 25: 1-2.

Tamura K, Dudley J, Nei M and Kumar S (2007). MEGA4: Molecular Evolutionary Genetics Analysis (MEGA) software version 4.0. Mol. Biol. Evol. 24: 1596-1599. http://dx.doi.org/10.1093/molbev/msm092

Thompson JD, Higgins DG and Gibson TJ (1994). Evolution of viral DNA-dependent DNA polymerases. Nucleic Acids Res. 22: 4673-4680. http://dx.doi.org/10.1093/nar/22.22.4673

Warner JR and McIntosh KB (2009). How common are extraribosomal functions of ribosomal proteins? Mol. Cell 34: 3-11. http://dx.doi.org/10.1016/j.molcel.2009.03.006

Wei F, Wang C and Shi Y (2013). Cloning and characterization of ribosomal protein S3a mRNA from Gymnocypris przewalskii. J. Shanghai Oc. Univ. 22: 815-820.

Wool IG (1996). Extraribosomal functions of ribosomal proteins. Trends Biochem. Sci. 21: 164-165. http://dx.doi. org/10.1016/S0968-0004(96)20011-8

$\mathrm{Xu}$ J, Chen K and Yao Q (2005). Fluorescent differential display analysis of the gene s3a related to NPV resistance in Bombyx mori L. Acta Entomol. Sin. 48: 347-352.

Zemzoumi K, Guilvard E, Sereno D, Preto A, et al. (1999). Cloning of a Leishmania major gene encoding for an antigen with extensive homology to ribosomal protein S3a. Gene 240: 57-65. http://dx.doi.org/10.1016/S0378-1119(99)00433-3

Zhao DQ, Zhou C, Shen GY, Liang G, et al. (2010). Molecular cloning and expression of phytoene synthase, lycopene beta-cyclase, and beta-carotene hydroxylase genes in persimmon (Diospyros kaki L.) fruits. Plant Mol. Biol. Rep. 29: 345-351. http://dx.doi.org/10.1007/s11105-010-0238-5

Zhu B, Liu C and Liu Q (2010a). Cloning and expression analysis of ribosomal protein S3a gene from Antheraea pernyi. Acta Sericol. Sin. 36: 507-512.

Zhu B, Liu C and Liu Q (2010b). Identification and prokaryotic expression analysis of S3a from Actiasselene. Acta Laser Biol Sin. 19: 74-81. 